\title{
MMP-9-hemopexin domain hampers adhesion and migration of colorectal cancer cells
}

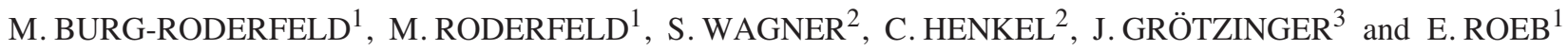 \\ ${ }^{1}$ Medical Clinic and Out-patient Department II (Gastroenterology), University Hospital Giessen and Marburg GmbH; ${ }^{2}$ Medical \\ Clinic III, University Hospital RWTH Aachen; ${ }^{3}$ Institute of Biochemistry, Christian-Albrechts-University Kiel, Germany
}

Received September 21, 2006; Accepted November 10, 2006

\begin{abstract}
Matrix metalloproteinases (MMPs), in particular MMP-2 and MMP-9, are involved in colon cancer progression and metastasis due to their ability to degrade extracellular matrix (ECM) components. In previous studies we described the MMP-9 hemopexin like domain (MMP-9-PEX) as an MMP-9 antagonist. In the present study it was examined whether recombinant MMP-9-PEX has an inhibitory effect on migration and adhesion of colorectal carcinoma cells. Furthermore, we searched for MMP-9 substrate binding sites within the MMP-9-PEX by surface plasmon resonance. Migration of SW620 and LS174 cells was investigated in a modified Boyden chamber assay. In the presence of $0.2 \mu \mathrm{g} / \mathrm{ml}$ MMP-9-PEX migration of SW620 was decreased by $34 \%$, while addition of $0.4 \mu \mathrm{g} / \mathrm{ml}$ diminished migration by $56 \%$. Migration of LS174 cells was not affected by MMP-9-PEX. Adhesion studies were performed on 96-well plates coated with gelatin, collagen type I, and laminin, respectively. In the presence of MMP-9-PEX, adhesion of SW620 cells to these coating substrates was significantly inhibited. Surface plasmon resonance studies revealed binding of collagen type I and IV, elastin, and fibrinogen to proMMP-9 as well as to MMP-9-PEX. However, equilibrium constants $\left(\mathrm{K}_{d}\right)$ indicated a higher affinity of proMMP-9 to the matrix proteins. This could indicate that there is more than one binding site for matrix components within the entire proMMP-9 molecule. Since migration and adhesion of metastatic colorectal carcinoma cells were reduced by MMP-9-PEX, this recombinant MMP-9 antagonist might be of therapeutical interest.
\end{abstract}

\section{Introduction}

Colorectal cancer contributes to a high mortality rate in Western society (1), where metastases are the main cause of

Correspondence to: Dr Elke Roeb, Medical Clinic and Outpatient Department II, Gastroenterology, University Hospital Giessen, Paul-Meimberg-Str. 5, D-35392 Giessen, Germany

E-mail: elke.roeb@innere.med.uni-giessen.de

Key words: MMP-9-PEX, proMMP-9, colorectal carcinoma, adhesion, migration, surface plasmon resonance death. The metastatic process includes migration crossing the basement membrane, intravasation into vessels, transport within the circulation, adhesion to endothelial cells, extravasation through the vessel wall, as well as sedation and proliferation in response to organ-specific factors at new sites $(2,3)$.

Degradation of extracellular matrix (ECM) respresents a hallmark for the development of secondary tumors due to metastasis (4). Cell adhesion and tumor cell migration depend on controlled ECM degradation (5), in which matrix metalloproteinases (MMP) play an important role (6). MMPs represent a family of zinc metallo-endopeptidases. Their activities are precisely regulated at the level of transcription, activation of the latent enzymes, interaction with specific ECM components, and inhibition by specific endogenous inhibitors. Cancer cells are known to recruit stromal MMP production for invasion and metastasis $(7,8)$.

Gelatinases (MMP-2 and MMP-9) are involved in colorectal cancer progression in animal models as well as in patients (9). MMP-2 and -9 differ from other MMPs by containing a fibronectin type II domain inside the catalytic domain (10). They are able to degrade basement membranes and components of the extracellular matrix such as type IV, V, VII, X, XI, and XIV collagens, gelatin, elastin, aggrecan, proteoglycan core protein, myelin basic protein, fibronectin, fibrillin-1, as well as precursors of TNF- $\alpha$, IL-1ß, and others (11). Especially MMP-9 expression correlated with local tumor growth (12), invasion, and intrahepatic metastasis, e.g. of hepatocellular carcinomas (13). On the other hand inhibition of MMP-9 expression blocked metastasis in a rat sarcoma model system (14). Furthermore, up-regulation of MMP-9 has been used in a portal blood assay to predict liver metastasis of colorectal cancer (15). Enhanced MMP-9 expression in primary colon tumors was associated with liver metastasis $(16,17)$ and MMP-9 expression was increased in biopsy samples from patients with colon cancer in comparison to healthy bowel tissue of the same patient (8).

MMP-9 differs from MMP-2 by a unique linker sequence of unknown function connecting the active site and the hemopexin domain (18). Substrate specificity of MMP-9 is tightly connected to the hemopexin domain which consists of four units of four-stranded antiparallel $\beta$ sheet stabilized on its 4-fold axis by a cation $\left(\mathrm{Zn}^{2+}\right)$. This domain constitutes a 4bladed $\beta$-propeller structure in which the blades are scarcely twisted (19). One remarkable property of MMP-9-PEX is the lack of stabilizing elements, present in all other related 
hemopexin-like structures. MMP-9-PEX is the first hemopexin structure determined in a dimeric state (20). The loss of few amino acid residues at the carboxy terminus inhibited substrate binding and inhibition by TIMP-1. Our previous study showed that MMP-9 activity is specifically reduced by its own hemopexin-like domain expressed in E.coli (21).

There is increasing evidence that a specific inhibition of MMP-9 activity might prevent metastasis. However, the exact molecular mechanisms of MMP-9 involvement in the metastatic process remain unknown. Identification of ECM components involved in this process and the investigation of highly specific MMP-9 antagonists may by useful for the development of new therapeutic approaches to lower the metastatic potential of colon carcinoma cells.

The aim of the present study was to demonstrate that MMP-9-PEX influences the migration of colon cancer cells. Furthermore, the influence of MMP-9-PEX on adhesion to ECM components was investigated. To specifically address the ability of MMP-9-PEX to bind ECM components, binding profiles of MMP-9-PEX for collagen type I/IV, gelatin, elastin, and fibrinogen were established using surface plasmon resonance (SPR).

\section{Materials and methods}

Materials. Culture reagents were obtained from Sigma-Aldrich (Steinheim, Germany), Gibco (Eggenstein, Germany), Sarstedt (Berlin, Germany) or PAA (Cölbe, Germany). All chemicals were purchased from Sigma-Aldrich (Munich, Germany), and GE Healthcare (Freiburg, Germany).

ProMMP-9 and MMP-9-PEX analysis. For antibody-based detection, buffer samples were separated by SDS-PAGE utilizing separating gels of $10 \%$ and $12.5 \%$ polyacrylamide for proMMP-9 and MMP-9-PEX, respectively and stacking gels of $3 \%$ polyacrylamide. Electrophoresis was performed at $40 \mathrm{~mA}$. Silver staining of polyacrylamide gels and Western blotting were performed according to a method described previously (22). Briefly, the proteins were transferred to a PVDF membrane at $2 \mathrm{~mA} / \mathrm{cm}^{2}$. Blots were blocked with TBS-N (pH 7.6) containing 10\% BSA, $20 \mathrm{mM}$ Tris, $137 \mathrm{mM}$ $\mathrm{NaCl}$, and $0.1 \%$ Nonidet $\mathrm{P} 40$, and were washed and incubated with antibodies against the $\mathrm{C}$ terminus of murine MMP-9 (AF 909, R\&D Systems, dilution 1:1000). Signals were visualized by enhanced chemiluminescence according to the manufacturer's instructions (ECL detection reagents, Amersham Biosciences).

Expression and purification of MMP-9-PEX. BL21 E. coli cells were transformed with the pGEX-5X-1-PEX plasmid and the MMP-9-PEX-GST fusion protein was expressed according to a method described by Roeb et al (21). Collected fractions were analyzed by SDS-PAGE (sodium dodecyl sulfate-polyacrylamide gel electrophoresis) and the MMP-9PEX-GST fusion protein was identified by immunoblot analysis as described above.

ProMMP-9 purification. Recombinant proMMP-9 was produced as described previously (23). Full-length mouse proMMP-9 was subcloned into a high-expression replication- deficient adenovirus type 5 with transcription under the control of the cytomegalovirus promotor. The $\sim 2.9-\mathrm{kbp}$ fragments of $\mathrm{pRc} / \mathrm{CMV}-\mathrm{mGelB}$ was integrated into the vector $\mathrm{p} \Delta \mathrm{E} 1 \mathrm{sp} 1 \mathrm{~A}-$ CMV-EGFP, depleted for EGFP. The integrity of all cloning boundaries was verified by sequencing and the entire insert was shuttled to the adenovirus plasmid (24). The adenovirus was selected, purified and expressed as previously described (23). Recombinant proMMP-9 was generated by infecting human hepatoma cells (HepG2), cultivated as described before (25), using a virus concentration of $2 \times 10^{8} \mathrm{pfu} / \mathrm{ml}$ in DMEM-F12 containing $5 \%(\mathrm{v} / \mathrm{v})$ heat-inactivated fetal calf serum (FCS), $100 \mathrm{mg} / \mathrm{l}$ streptomycin, and $60 \mathrm{mg} / \mathrm{l}$ penicillin for $16 \mathrm{~h}$. Cells were cultured for $24 \mathrm{~h}$ with renewed medium, and thereafter grown under serum-free conditions for $48 \mathrm{~h}$ before harvest. The harvested HepG2 conditioned media were sterile-filtered, and dialyzed against 'native buffer' (NB) containing $100 \mathrm{mM}$ Tris/HCl, pH 7.5; $50 \mathrm{mM} \mathrm{NaCl} ; 1 \mathrm{mM} \mathrm{CaCl}_{2} ; 0.02 \%$ (w/v) PEG6000. The recombinant proMMP-9 was isolated from the pre-purified samples in a one-step affinity chromatography utilizing gelatin-sepharose. Protein purity and integrity was checked by SDS-PAGE, subsequent silver staining, and Western blot analysis.

Colon cancer cells and cell treatment. Human colon cancer cell lines SW620 (ATCC, CCL-227) and LS174 (ATCC, CL-188) were employed for this study. SW620 and LS174 cells were maintained in RPMI-1640 supplemented with $10 \%$ FCS, streptomycin $(10 \mathrm{mg} / \mathrm{l})$, and penicillin (10 U/l). Cells were grown at $5 \% \mathrm{CO}_{2}$ and $37^{\circ} \mathrm{C}$ in a water saturated atmosphere. One day prior to experiments cells were seeded to provide a final cell density of $60-70 \%$ confluence.

Boyden chamber experiments. Transwell $8-\mu \mathrm{m}$ pore membrane inserts (18-mm standard PCTE filters, Neuro Probe, Gaithersburg, USA) were activated for $20 \mathrm{~min}$ at $50^{\circ} \mathrm{C}$ with $0.5 \%$ acetic acid. The activated membranes were coated with $5 \mathrm{mg} / \mathrm{l}$ gelatin solution for $1 \mathrm{~h}$ at $100^{\circ} \mathrm{C}$ (26). After drying $\left(100^{\circ} \mathrm{C}, 1 \mathrm{~h}\right.$ on Whatman paper) the inserts were placed in a blind well chemotaxis chamber (Neuro Probe). The lower compartment was filled with $50 \mu \mathrm{g} / \mathrm{ml}$ collagen type I (from human placenta) containing fibroblast conditioned medium according to the method of Wach et al (27), which was used as chemoattractant. Prior to seeding cells were detached by trypsin treatment, rinsed with FCS-free medium and diluted to $2.5 \times 10^{5}$ cells $/ \mathrm{ml}$. Cell suspension $(800 \mu \mathrm{l})$ with PEX or BSA as reference protein or without further supplements was added to the upper chamber. Chambers were placed in a humified tissue incubator, containing $5 \% \mathrm{CO}_{2}$ for $16 \mathrm{~h}$ at $37^{\circ} \mathrm{C}$. Cells on the upper surface of the transwell inserts were removed using a cotton swab and those on the lower surface of the membranes were fixed with $10 \%$ methanol and stained with hematoxylin and eosin. Membranes were rinsed with deionized water, dried, and examined using light microscopy. The number of migrated cells in five optical fields (magnification $\mathrm{x} 400$ ) was averaged.

Attachment assay. Attachment assays were performed in 96-well plates. Gelatin-, collagen type I- or laminin-coated plates were used. Plates were coated with $0.4 \%$ gelatin in deionized water for $2 \mathrm{~h}$ at $37^{\circ} \mathrm{C}$. For collagen coating, wells 
were incubated with collagen type I solution $[50 \mu \mathrm{g} / \mathrm{ml}$ phosphate-buffered saline (PBS), prepared according to the manufacturer's instructions] for $2 \mathrm{~h}$ at $0^{\circ} \mathrm{C}$, then the solution was removed and the plates were dried at $0^{\circ} \mathrm{C}$. Fifteen $\mu \mathrm{g}$ laminin per ml PBS was used for laminin coating. Wells were filled with laminin solution and incubated at $4^{\circ} \mathrm{C}$ overnight. Colon carcinoma cells were harvested by trypsin incubation and resuspended in medium. Fifty-thousand cells per well were used for the assay. Standard curves for every plate were generated by seeding 12500, 25000, 50000 and 100000 cells per well in duplicate respectively. Plates were incubated overnight in a humified tissue incubator with $5 \% \mathrm{CO}_{2}$ and at $37^{\circ} \mathrm{C}$. After removal of the supernatant, the attached cells were fixed for $10 \mathrm{~min}$ using $1 \%$ glutaraldehyde and stained with $0.1 \%$ crystal violet solution for $25 \mathrm{~min}$. Wells were rinsed with deionized water and treated with $0.1 \%$ Triton $\mathrm{X}-100$ solution. Absorption of the resolved crystal violet was measured photometrically at $540 \mathrm{~nm}$.

Surface plasmon resonance studies. Gelatin, collagen type I, and type IV was covalently immobilized to a carboxymethyl dextran matrix (Fisons, Loughborough, UK) at $50 \mu \mathrm{g} / \mathrm{ml}$ respectively for $2 \mathrm{~min}$ in $10 \mathrm{mM}$ sodium acetate buffer, $\mathrm{pH} 3.9$ as recommended by the manufacturer. Elastin was immobilized stepwise, starting with $10 \mu \mathrm{l}$ elastin stock solution $1(200 \mathrm{mg} / \mathrm{ml}$ PBS, pH 6.0) + $90 \mu 1$ phosphate-buffered saline, $\mathrm{pH} 6.0$ followed by the addition of $10 \mu 110 \mathrm{mM}$ acetic acid. Twohundred $\mu 1$ elastin stock solution 1 was injected in a second step. Finally, $200 \mu 1$ elastin stock solution $2(250 \mathrm{mg} / \mathrm{ml}$ aqua dest.) was added. Elastin was immobilized to the membrane for $5 \mathrm{~min}$. Fibrinogen [10 $\mu \mathrm{l}$ fibrinogen stock solution $(100 \mathrm{mg} / \mathrm{ml}$ PBS, pH 6.0) + $90 \mu 110$ mM NaAc pH 4.5] was covalently immobilized to the carboxymethyl dextran for $5 \mathrm{~min}$. Binding experiments were performed at a controlled temperature $\left(15^{\circ} \mathrm{C}\right)$ with different concentrations of proMMP-9 and MMP-9-PEX using the IASYSTEM (Fisons) optical biosensor. Association was monitored for at least $2 \mathrm{~min}$. The sample was replaced by PBS containing $0.1 \%$ Triton X-100 solution (PBS-T), pH 7.4 and dissociation was monitored accordingly before the cuvette was regenerated with $10 \mathrm{mM} \mathrm{HCl}$ and equilibrated again. Association and dissociation affinograms were analyzed by non-linear regression with FASTfit software (Fisons), which uses the Marquardt-Levenburg algorithm for iterative data fitting.

Statistical analysis. Statistical significance $(\mathrm{p}<0.05)$ between controls and samples $(n=8-145)$ was determined by unpaired t-tests postulating different variances (Welch's t-test) and SED (standard error of differences) was calculated as SD (standard deviation) of the sample distribution (sample mean).

\section{Results}

Purification and characterization of MMP-9-PEX. Recombinant GST-MMP-9-PEX fusion protein was expressed in E. coli (BL21). Bacterial lysates were subjected to SDSPAGE and subsequent Western blotting. Expression revealed a GST-MMP-9-PEX fusion protein corresponding to a molecular mass of $52 \mathrm{kDa}$ detected by anti-murine MMP-9 antibodies. Recombinant GST-MMP-9-PEX digested by factor Xa and

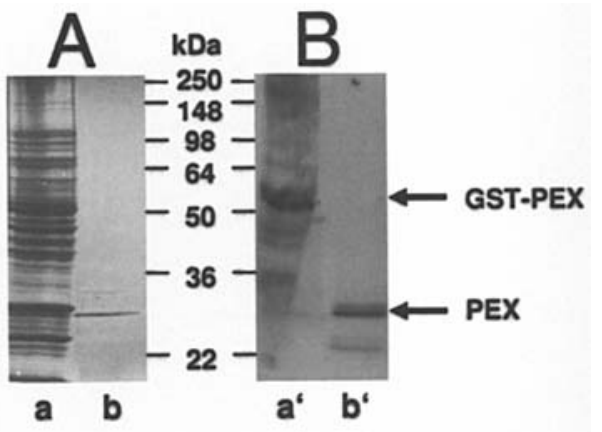

Figure 1. Purification and characterization of recombinant MMP-9 PEX. A, coomassie-stained SDS-PAGE of bacterial lysates (a) and of the purified MMP-9-PEX (b); B, anti-murine MMP-9 Western blot analysis of bacterial lysates (a') and of the purified MMP-9-PEX (b').

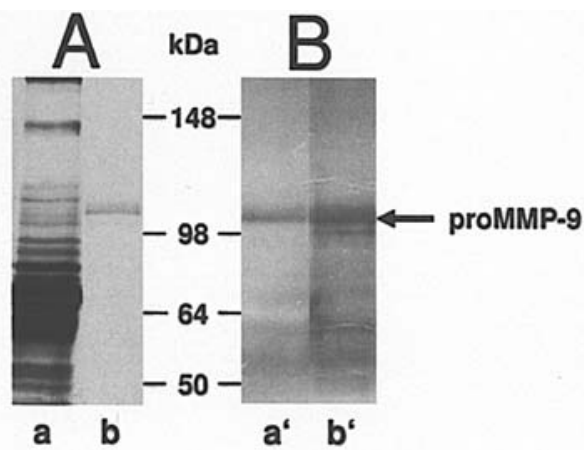

Figure 2. Purification and characterization of proMMP-9. A, silver-stained SDS-PAGE of cell culture supernatant of transfected cells (a) and of the purified proMMP-9 (b); B, anti-murine MMP-9 Western blot analysis of cell culture supernatant of transfected cells (a') and of the purified proMMP-9 (b').

the cleavage products were isolated by gel filtration in a second column purification step. After final purification a $25-\mathrm{kDa}$ protein was detected by coomassie-stained SDS-PAGE (Fig. 1A). The identity of MMP-9-PEX was proved by Western blot analysis (Fig. 1B) with specific anti-murine MMP-9 antibodies.

Purification and characterization of proMMP-9. Recombinant proMMP-9 was enriched and purified from conditioned cell culture medium by affinity chromatography using gelatinsepharose. Fifty to two-hundred $\mu \mathrm{g}$ (of $\sim 80-90 \%$ purity) of proMMP-9 were extracted from $200 \mathrm{ml}$ cell culture medium. Conditioned cell culture media and purified material were analysed by silver-stained SDS-PAGE (Fig. 2A) and Western blotting (Fig. 2B).

Migration of colon carcinoma cells in the presence of MMP9-PEX. To investigate whether MMP-9-PEX influences the migration of colon carcinoma cells, we examined the motility of SW620 and LS174 cells in Boyden chamber experiments. Type I collagen containing fibroblast conditioned medium was used as chemoattractant. After incubation for $16 \mathrm{~h}$, migrated cells on the underside of the gelatin-coated membrane were counted. Experiments were performed in triplicate. The median cell number of five optic fields per membrane was determined. Data were normalized by setting the number of 


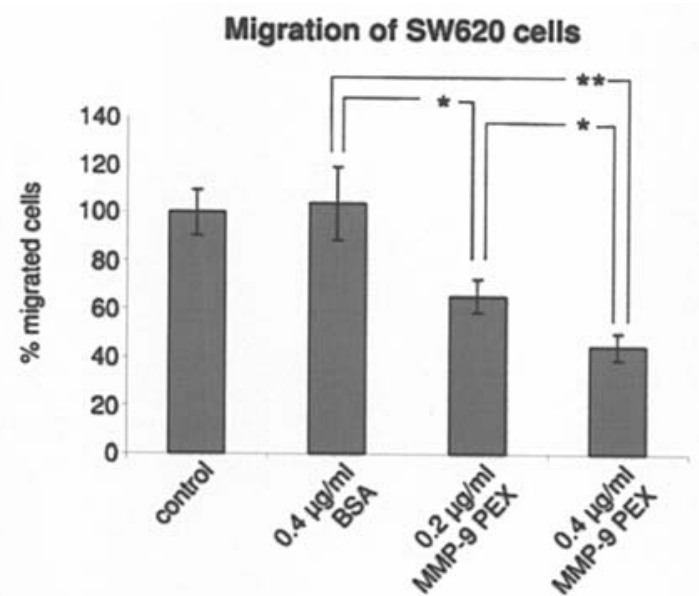

Figure 3. Effect of MMP-9-PEX addition on migration of SW620 cells. Relative migration of SW620 cells was measured in Boyden chambers without MMP-9-PEX, with addition of $0.4 \mu \mathrm{g} / \mathrm{ml} \mathrm{BSA}$ as reference protein and with 0.2 and $0.4 \mu \mathrm{g} / \mathrm{ml}$ MMP-9-PEX. Cells on the lower surface of the membrane were counted after staining with hematoxylin and eosin and the cell number of five optical fields was averaged. y-axis, number of cells in \%. Each bar represents the mean \pm SED of three chambers. ${ }^{*} \mathrm{p}<0.05 ;{ }^{* *} \mathrm{p}<0.001$.

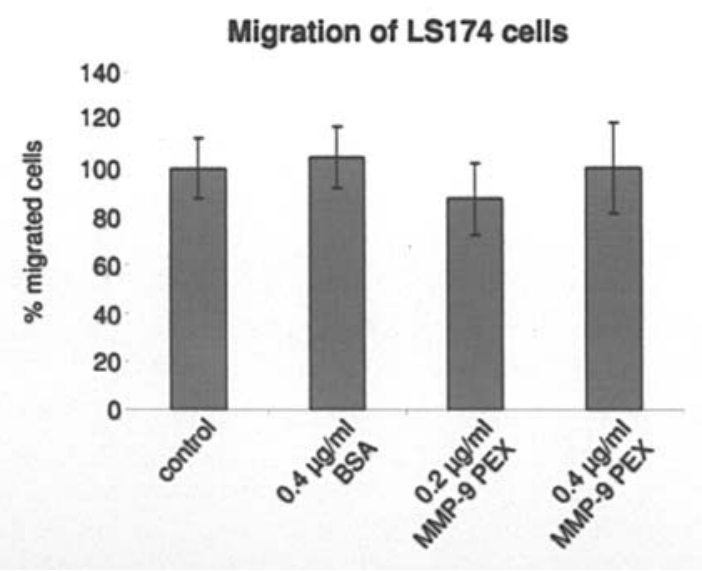

Figure 4. Effect of MMP-9-PEX addition on migration of LS174 cells. Relative migration of LS174 cells was measured in Boyden chambers without MMP-9-PEX, with addition of $0.4 \mu \mathrm{g} / \mathrm{ml} \mathrm{BSA}$ as reference protein and with 0.2 and $0.4 \mu \mathrm{g} / \mathrm{ml}$ MMP-9-PEX. Cells on the lower surface of the membrane were counted after staining with hematoxylin and eosin and the cell number of five optical fields was averaged. y-axis, number of cells in \%. Each bar represents the mean \pm SED of three chambers.

migrated control cells (no MMP-9-PEX or BSA) to 100\%. Data are presented as mean \pm SED. Metastasis-derived SW620 cells showed a dose-dependent decrease in migration through the membrane. The addition of $0.2 \mu \mathrm{g} / \mathrm{ml}$ MMP-9-PEX led to a $34.4 \pm 6.8 \%$ reduction $(\mathrm{p}=0.034)$ and $0.4 \mu \mathrm{g} / \mathrm{ml}$ to a $55.5 \pm 5.4 \%$ reduction of migration ( $\mathrm{p}=0.003$, Fig. 3 ). In contrast, migration of primary tumor-derived LS174 cells remained unchanged after addition of MMP-9-PEX in different concentrations (Fig. 4).

Adhesion of SW620 colon carcinoma cells in the presence of $M M P-9-P E X$. Since adhesion of tumor cells to endothelial cells is mediated by ECM proteins, we investigated the adhesion of SW620 cells to gelatin-, collagen type I-, and laminin-

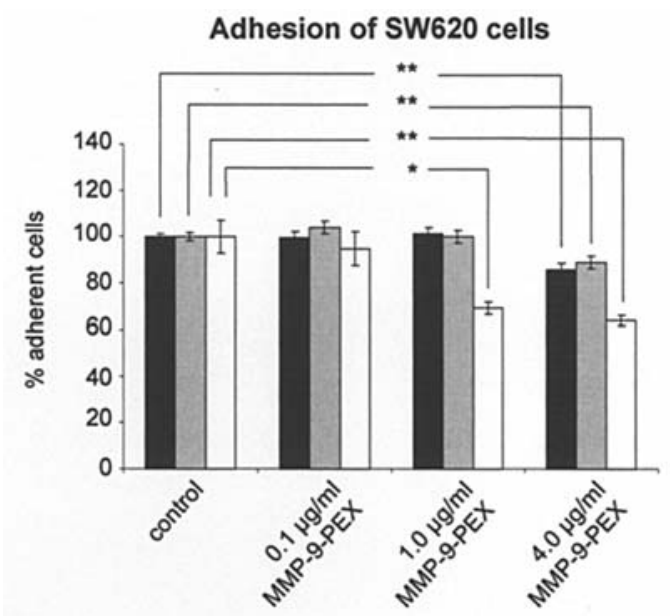

Figure 5. MMP-9-PEX addition reduces adhesion of SW620 cells on gelatin-, collagen type I- and laminin-coated surfaces. Relative adhesion of SW620 cells was measured in coated 96-well plates without MMP-9-PEX and with $0.1,1.0$ and 4.0 $\mu \mathrm{g} / \mathrm{ml}$ MMP-9-PEX. Adherent cells were stained with crystal violet. After washing and treatment with $0.1 \%$ Triton X-100 solution resolved crystal violet was measured photometrically at $540 \mathrm{~nm}$. Relative adhesion was calculated using a standard curve. $y$-axis, relative cell adhesion in $\%$. Each bar represents the mean \pm SED of eight values. Collagen type I, black bars; laminin, grey bars; gelatin, white bars; ${ }^{*} \mathrm{p}<0.05 ;{ }^{* *} \mathrm{p}<0.001$.

coated surfaces either in the presence or absence of MMP-9PEX. Cells were seeded to coated 96-well plates and incubated for $16 \mathrm{~h}$ with $0.1,1.0$, and $4.0 \mu \mathrm{g} / \mathrm{ml}$ MMP-9-PEX or $4 \mu \mathrm{g} / \mathrm{ml}$ BSA as control. Relative adherence was measured by setting the number of adherent cells without MMP-9-PEX to $100 \%$. Data were calculated as mean \pm SED of 8 wells respectively. The adhesion of SW620 cells on collagen type I was reduced by $14.1 \pm 2.6 \%$ while adhesion to laminin decreased by $11.2 \pm 2.7 \%$ in the presence of MMP-9-PEX $(4 \mu \mathrm{g} / \mathrm{ml})$. Adhesion to gelatin was also affected. The number of adherent cells was reduced by $30.6 \pm 2.8 \%(1 \mu \mathrm{g} / \mathrm{ml}$ MMP-9-PEX) and by $36.2 \pm 2.2 \%(4 \mu \mathrm{g} / \mathrm{ml})$ (Fig. 5). Thus a significant reduction of SW620 cell adhesion by MMP-9-PEX was observed for all surfaces examined.

Binding of MMP-9-PEX to gelatin, collagen type I and IV, elastin and fibrinogen. In the present study we measured the affinity of MMP-9-PEX to physiological ECM substrates (collagen type I and IV, elastin, fibrinogen) in comparison to the entire enzyme using representative surface plasmon resonance experiments are shown in Fig. 6 as described in Materials and methods. Immobilisation of other ECM components, such as laminin, decorin, aggrecan, and fibronectin, was not effective and due to this SPR was abrogated. The association $\left(\mathrm{k}_{\text {on }}\right)$ and dissociation $\left(\mathrm{k}_{\text {off }}\right)$ rate constants of proMMP-9 and MMP-9-PEX for different substrates were determined and the equilibrium constant $\left(\mathrm{K}_{\mathrm{d}}\right)$ was calculated respectively (Tables I and II).

MMP-9-PEX exhibited binding to gelatin, collagen type I and IV, elastin, and fibrinogen. The highest affinities were found for gelatin $\left(K_{d}=295 \mathrm{nM}\right)$, collagen type $\mathrm{I}\left(\mathrm{K}_{\mathrm{d}}=444 \mathrm{nM}\right)$, and collagen type IV $\left(\mathrm{K}_{\mathrm{d}}=655 \mathrm{nM}\right)$. Weaker affinities were observed for elastin $\left(\mathrm{K}_{\mathrm{d}}=1.1 \mu \mathrm{M}\right)$ and for fibrinogen $\left(\mathrm{K}_{\mathrm{d}}=\right.$ $1.26 \mu \mathrm{M})($ Table I). In contrast to that proMMP-9 showed very high affinities for collagen type IV $\left(\mathrm{K}_{\mathrm{d}}=30.8 \mathrm{pM}\right)$ and 


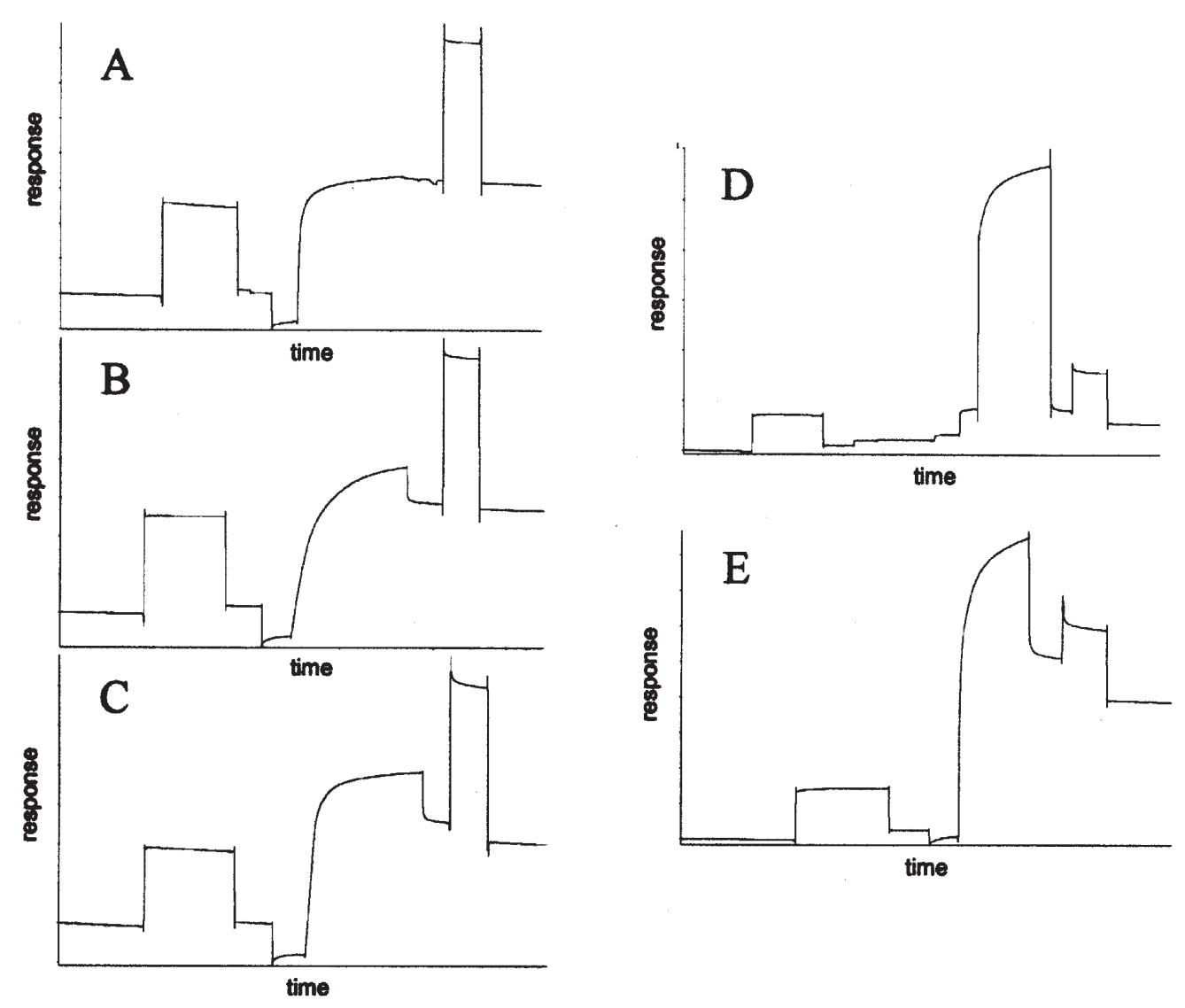

Figure 6. Immobilisation of ECM proteins. Covalent binding profiles of ECM components to a carboxymethyl dextran matrix. Immobilisation of: A, gelatin; B, collagen type I; C, collagen type IV; D, elastin; E, fibrinogen.

Table I. Kinetic ( $\mathrm{k}_{\mathrm{on}}$, association; $\mathrm{k}_{\mathrm{off}}$, dissociation) and equibrilium ( $\mathrm{K}_{\mathrm{d}}$, dissociation) constants for the binding of MMP-9PEX to ECM proteins.

\begin{tabular}{lccc}
\hline ECM protein & $\mathrm{k}_{\text {on }}$ & $\mathrm{k}_{\text {off }}$ & $\mathrm{K}_{\mathrm{d}}$ \\
$\mathrm{M}$ & $\mathrm{s}^{-1} \mathrm{~s}^{-1}$ & & $\mathrm{M}$ \\
\hline Gelatin & $5.62 \times 10^{4} \pm 2.65 \times 10^{3}$ & $3.71 \times 10^{-3} \pm 2.29 \times 10^{-4}$ & $2.95 \times 10^{-7} \pm 3.84 \times 10^{-8}$ \\
Collagen type I & $4.22 \times 10^{4} \pm 1.20 \times 10^{3}$ & $5.33 \times 10^{-3} \pm 2.88 \times 10^{-4}$ & $4.44 \times 10^{-7} \pm 6.21 \times 10^{-8}$ \\
Collagen type IV & $7.45 \times 10^{3} \pm 5.61 \times 10^{2}$ & $3.93 \times 10^{-3} \pm 2.59 \times 10^{-4}$ & $6.55 \times 10^{-7} \pm 1.18 \times 10^{-7}$ \\
Elastin & $8.61 \times 10^{2} \pm 4.31 \times 10^{1}$ & $9.50 \times 10^{-4} \pm 3.24 \times 10^{-5}$ & $1.10 \times 10^{-6} \pm 9.29 \times 10^{-8}$ \\
Fibrinogen & $6.51 \times 10^{3} \pm 3.75 \times 10^{2}$ & $4.36 \times 10^{-3} \pm 1.18 \times 10^{-4}$ & $1.26 \times 10^{-6} \pm 1.23 \times 10^{-7}$ \\
\hline
\end{tabular}

Table II. Kinetic ( $\mathrm{k}_{\mathrm{on}}$, association; $\mathrm{k}_{\mathrm{off}}$, dissociation) and equibrilium $\left(\mathrm{K}_{\mathrm{d}}\right.$, dissociation) constants for the binding of the proMMP-9 to ECM proteins.

\begin{tabular}{lccc}
\hline EECM protein & $\begin{array}{c}\mathrm{k}_{\text {on }} \\
\mathrm{M}^{-1} \mathrm{~s}^{-1}\end{array}$ & $\begin{array}{c}\mathrm{k}_{\text {off }} \\
\mathrm{s}^{-1}\end{array}$ & $\begin{array}{c}\mathrm{K}_{\mathrm{d}} \\
\mathrm{M}\end{array}$ \\
\hline Gelatin & $7.18 \times 10^{5} \pm 5.47 \times 10^{4}$ & $1.89 \times 10^{-2} \pm 9.77 \times 10^{-4}$ & $3.29 \times 10^{-8} \pm 4.20 \times 10^{-9}$ \\
Collagen type I & $5.74 \times 10^{9} \pm 4.07 \times 10^{8}$ & $4.66 \times 10^{-2} \pm 3.28 \times 10^{-3}$ & $4.28 \times 10^{-8} \pm 6.06 \times 10^{-9}$ \\
Collagen type IV & $1.14 \times 10^{9} \pm 1.00 \times 10^{8}$ & $6.85 \times 10^{-3} \pm 5.34 \times 10^{-4}$ & $3.08 \times 10^{-11} \pm 5.12 \times 10^{-12}$ \\
Elastin & $9.36 \times 10^{7} \pm 1.19 \times 10^{7}$ & $5.02 \times 10^{-3} \pm 4.03 \times 10^{-4}$ & $6.28 \times 10^{-11} \pm 1.30 \times 10^{-11}$ \\
Fibrinogen & $4.79 \times 10^{7} \pm 4.70 \times 10^{6}$ & $1.13 \times 10^{-2} \pm 1.05 \times 10^{-3}$ & $1.51 \times 10^{-9} \pm 2.88 \times 10^{-10}$ \\
\hline
\end{tabular}


Table III. Interaction between MMP-9-PEX and ECM proteins.

\begin{tabular}{lcc}
\hline ECM protein & Adhesion & SPR \\
\hline Gelatin & +++ & +++ \\
Collagen type I & ++ & +++ \\
Collagen type IV & $\mathrm{ND}^{\mathrm{a}}$ & ++ \\
Laminin & + & $\mathrm{ND}^{\mathrm{a}}$ \\
Elastin & $\mathrm{ND}^{\mathrm{a}}$ & + \\
Fibrinogen & $\mathrm{ND}^{\mathrm{a}}$ & + \\
\hline
\end{tabular}

${ }^{\mathrm{a} N D}$, not detected.

elastin $\left(\mathrm{K}_{\mathrm{d}}=62.8 \mathrm{pM}\right)$. The corresponding binding for MMP-9PEX was $\sim 10^{4}$ times weaker. The affinity of proMMP-9 to fibrinogen $\left(\mathrm{K}_{\mathrm{d}}=1.51 \mathrm{nM}\right)$ was found to be $\sim 10^{3}$ times higher than the corresponding MMP-9-PEX affinity. Concerning gelatin and collagen type I equilibrium constants for complex formation with proMMP-9 $\left(\mathrm{K}_{\mathrm{d}}=32.9 \mathrm{nM}, \mathrm{K}_{\mathrm{d}}=42.8 \mathrm{nM}\right.$ respectively) were approximately 10 times higher than the values for MMP-9-PEX. In summary, we observed a similar affinity for MMP-9-PEX to gelatin and collagen type I.

\section{Discussion}

Tumor cell traversal of basement membrane barriers is the result of the acquisition of an invasive phenotype: tumor cells acquired the ability to attach to the ECM, to degrade matrix components, and then migrate through these matrix defects. Metastasis is therefore a multistep process involving numerous tumor-cell host interaction. These interactions are defined by the invasive phenotype that can be separated into three steps: attachment, local proteolysis, and migration $(7,28-30)$. Hence local ECM proteolysis is essential for tumor invasion and depends strongly on the activity of MMPs. Commonly, MMPs play a major role in cell motility in different types of tissue (31). The role of MMPs due to cell invasion and metastasis has been the subject of a variety of studies in the last year (32-36). We have recently demonstrated a positive correlation between MMP-9 expression and development of colorectal carcinomas (8). Others found that active MMP-9 was more strongly expressed in colon carcinomas from patients with liver metastases than from patients without metastasis (16).

In the last decade several synthetic inhibitors of MMPs were developed and went rapidly into clinical trials. In most of these trials the inhibitors were tested in patients with end-stage disease without the complete knowledge of the complex mechanism of action of MMPs in cancer (37). These trials failed to reach their end points of increased survival. Therefore critical assessments of the criteria for successful therapeutic MMP-inhibition were provided $(36,38-40)$. In conclusion these results suggest that a successful anticancer inhibitor must possess MMP selectivity against those MMP subtypes whose involvement is critical (41). MMP-9 could be a key therapeutic target in patients with colorectal cancer (42). Due to this MMP-9 inhibition might be beneficial in colorectal tumor progression. Recently we characterized the MMP-9 C-terminal hemopexin domain and demonstrated its MMP-9 antagonistic activity (21). Furthermore we showed that migration of malignant melanoma cells overexpressing MMP-9 was reduced in the presence of MMP-9-PEX. Therefore, MMP-9-PEX might have an impact on the metastatic potential of tumor cells.

In the present study we examined the effect of MMP-9PEX on adhesion and migration of colon cancer cell lines SW620 and LS174, derived from metastases and primary tumor material respectively. Two of the three central steps of the metastatic cascade, cell adhesion and cell migration, were inhibited by MMP-9-PEX in highly metastatic SW620 cells. Interestingly, the motility of primary tumor-derived LS174 cells remained unaffected by MMP-9-PEX. In the presence of MMP-9-PEX we further observed a decrease in cell adhesion to matrix proteins (collagen type I, gelatin, and laminin). The antagonistic effects of MMP-9-PEX on migration and adhesion of colon carcinoma cells might lower their invasive potential.

The gelatin binding property of MMP-9-PEX has already been described (21). We now focused on interactions between MMP-9-PEX and physiological ECM components, such as collagen type I. The interactions of MMP-9-PEX and ECM proteins were summarized in Table III. We performed surface plasmon resonance (SPR) studies with selected matrix proteins according to Björklund and Koivunnen (43). In addition to collagen type I and IV, elastin, and fibrinogen the binding properties of MMP-9-PEX to gelatin was tested and thus the high affinity interactions between MMP-9-PEX and gelatin, published earlier, were confirmed (21).

A comparable binding capacity could be identified between MMP-9-PEX and collagen type $\mathrm{I}\left(\mathrm{K}_{\mathrm{d}}=444 \mathrm{nM}\right)$. Interestingly MMP-9 is unable to cleave soluble or fibrillar collagen type I (44). The binding of MMP-9 to collagen type I has already been described (10). It was postulated that only the N-terminal portion of the molecule should be responsible for gelatin binding. In a recent study, however, a unique collagen-binding domain (CBD) consisting of three fibronectin type II-like modules was identified for MMP-9 and MMP-2 (45). This CBD was able to bind a series of collagen types including collagen type I/IV. Recombinant CBDs of MMP-2 and MMP-9 were shown to inhibit gelatinolytic activity of both enzymes and vice versa. Interestingly inactive mutants of MMP-2 and MMP-9 had a stronger inhibitory effect on gelatinolysis indicating unresolved interactions between the CBD and other parts of the enzyme. This observation is consistent with previous results demonstrating that the hemopexin-like domain of MMP-2 is involved in collagenolysis (46). Due to our results MMP-9-PEX is involved in the binding of collagen type I and gelatin. Digestion of collagen type I, the initial step of ECM degradation (47), is promoted by trypsin, which is co-expressed with MMPs in colorectal carcinomas (36). Furthermore trypsin activates a number of pro-collagenases, including proMMP-2 and proMMP-9. In this context the close localization of MMP-9 and collagen type I might be associated with the colorectal cancer promoting effect of trypsin, e.g. degradation of collagen type I and activation of MMP-9. Our results imply that these interactions may be reduced in the presence of MMP-9-PEX. 
Binding capacities of MMP-9-PEX for collagen type IV, elastin, and fibrinogen, which are all MMP-9 substrates, have also been identified (43). The equilibrium constants between MMP-9-PEX and the substrates collagen IV, elastin and fibrinogen were lower than for gelatin and collagen type I. For the entire enzyme, however, we observed high affinities for collagen type IV, elastin, and fibrinogen. Contrary to our results Olson et al found low affinities of proMMP-9 for collagen type IV $\left(\mathrm{K}_{\mathrm{d}}=2.15 \mu \mathrm{M}\right)$ and the purified $\alpha 2(\mathrm{IV})$ chain of collagen type IV $\left(\mathrm{K}_{\mathrm{d}} \sim 45 \mathrm{nM}\right)$. Others also described a degradation of laminin (48), fibrinogen (49), and elastin (50) by MMP-9, but the kinetics of the interactions or binding affinities for the substrates were not presented. It has been proposed recently that MMP-9 interacts with several cell surface components namely the surface-associated $\alpha 2$ (IV) chain of collagen type IV, hyaluron receptor CD44, RECK (reversion-inducing-cystein-rich protein with Kazal motifs), and LRP (low-density lipoprotein receptor-related protein) (51). This type of interaction positively regulates enzymatic activation and activity (51). A major dilemma in the understanding of MMP-9 function is how the released protease is targeted to the right location and how its activity is controlled within the extracellular space. The interaction of MMP-9PEX with physiological ECM components, such as collagen type I and IV, elastin, and fibrinogen, may play a critical role in localization of the MMP-9 to focus and restrict its activity to the pericellular environment.

Our results demonstrate that migration of metastatic colorectal cancer cells is reduced in the presence of MMP-9PEX. Furthermore the adhesion of these cells on matrix components is inhibited by MMP-9-PEX. This indicates that the interactions of MMP-9 with gelatin, collagen type I, and laminin were reduced by MMP-9-PEX. The underlying molecular mechanisms have to be clarified in further studies. From our data we conclude that the hemopexin-like domain of MMP-9 contains exosides for collagen type I and for gelatin. Furthermore, our data show that MMP-9-PEX has additional binding sites for collagen type IV, elastin, and fibrinogen.

We provide new aspects of MMP-9 binding properties and show that MMP-9-PEX might be a promising approach for antimetastatic therapy. The impact of MMP-9-PEX on colorectal cancer progression, however, needs further evaluation.

\section{Acknowledgements}

The authors are grateful for the expert technical assistance of Katja Strick. This work was supported by grants from the Deutsche Forschungsgemeinschaft (SFB 542 TP C3, RO 957/ 6-1), and from Giessen University.

\section{References}

1. Labianca R, Pessi MA and Zamparelli G: Treatment of colorectal cancer. Current guidelines and future prospects for drug therapy. Drugs 53: 593-607, 1997.

2. Fidler IJ: Critical factors in the biology of human cancer metastasis: twenty-eighth G.H.A. Clowes memorial award lecture. Cancer Res 50: 6130-6138, 1990.

3. Blumenthal RD, Hansen HJ and Goldenberg DM: Inhibition of adhesion, invasion, and metastasis by antibodies targeting CEACAM6 (NCA-90) and CEACAM5 (carcinoembryonic antigen). Cancer Res 65: 8809-8817, 2005.
4. Nakajima M, Morikawa K, Fabra A, Bucana CD and Fidler IJ: Influence of organ environment on extracellular matrix degradative activity and metastasis of human colon carcinoma cells. J Natl Cancer Inst 82: 1890-1898, 1990.

5. Shapiro SD: Matrix metalloproteinase degradation of extracellular matrix: biological consequences. Curr Opin Cell Biol 10: 602-608, 1998.

6. Woessner JF Jr: Matrix metalloproteinases and their inhibitors in connective tissue remodeling. FASEB J 5: 2145-2154, 1991.

7. Stetler-Stevenson WG, Aznavoorian S and Liotta LA: Tumor cell interactions with the extracellular matrix during invasion and metastasis. Annu Rev Cell Biol 9: 541-573, 1993.

8. Roeb E, Dietrich CG, Winograd R, et al: Activity and cellular origin of gelatinases in patients with colon and rectal carcinoma: differential activity of matrix metalloproteinase-9. Cancer 92: 2680-2691, 2001.

9. Mook OR, Frederiks WM and van Noorden CJ: The role of gelatinases in colorectal cancer progression and metastasis. Biochim Biophys Acta 1705: 69-89, 2004.

10. Allan JA, Docherty AJ, Barker PJ, Huskisson NS, Reynolds JJ and Murphy G: Binding of gelatinases A and B to type-I collagen and other matrix components. Biochem J 309: 299-306, 1995.

11. Johansson N, Ahonen M and Kahari VM: Matrix metalloproteinases in tumor invasion. Cell Mol Life Sci 57: 5-15, 2000.

12. Van den Steen PE, Opdenakker G, Wormald MR, Dwek RA and Rudd PM: Matrix remodelling enzymes, the protease cascade and glycosylation. Biochim Biophys Acta 1528: 61-73, 2001.

13. Sakamoto Y, Mafune K, Mori M, et al: Overexpression of MMP-9 correlates with growth of small hepatocellular carcinoma. Int J Oncol 17: 237-243, 2000.

14. Hua $J$ and Muschel RJ: Inhibition of matrix metalloproteinase-9 expression by a ribozyme blocks metastasis in a rat sarcoma model system. Cancer Res 56: 5279-5284, 1996.

15. Ishida H, Murata N, Tada M, et al: Determining the levels of matrix metalloproteinase- 9 in portal and peripheral blood is useful for predicting liver metastasis of colorectal cancer. Jpn J Clin Oncol 33: 186-191, 2003.

16. Matsuyama Y, Takao S and Aikou T: Comparison of matrix metalloproteinase expression between primary tumors with or without liver metastasis in pancreatic and colorectal carcinomas. J Surg Oncol 80: 105-110, 2002.

17. Zucker S and Vacirca J: Role of matrix metalloproteinases (MMPs) in colorectal cancer. Cancer Metastasis Rev 23: 101-117, 2004.

18. Van den Steen PE, Van AI, Hvidberg V, et al: The hemopexin and O-glycosylated domains tune gelatinase B/MMP-9 bioavailability via inhibition and binding to cargo receptors. $\mathrm{J} \mathrm{Biol}$ Chem 281: 18626-18637, 2006.

19. Li J, Brick P, O'Hare MC, et al: Structure of full-length porcine synovial collagenase reveals a $\mathrm{C}$-terminal domain containing a calcium-linked, four-bladed beta-propeller. Structure 3: 541-549, 1995.

20. Cha H, Kopetzki E, Huber R, Lanzendorfer M and Brandstetter H: Structural basis of the adaptive molecular recognition by MMP9. J Mol Biol 320: 1065-1079, 2002.

21. Roeb E, Schleinkofer K, Kernebeck T, et al: The matrix metalloproteinase-9 (mmp-9) hemopexin domain is a novel gelatin binding domain and acts as an antagonist. J Biol Chem 277: 50326-50332, 2002.

22. Merril CR, Goldman D, Sedman SA and Ebert MH: Ultrasensitive stain for proteins in polyacrylamide gels shows regional variation in cerebrospinal fluid proteins. Science 211: 1437-1438, 1981.

23. Roderfeld M, Weiskirchen R, Wagner S, et al: Inhibition of hepatic fibrogenesis by matrix metalloproteinase- 9 mutants in mice. FASEB J 20: 444-454, 2006.

24. Weiskirchen R, Kneifel J, Weiskirchen S, van de LE, Kunz D and Gressner AM: Comparative evaluation of gene delivery devices in primary cultures of rat hepatic stellate cells and rat myofibroblasts. BMC Cell Biol 1: 4, 2000.

25. Roeb E, Behrmann I, Grotzinger J, Breuer B and Matern S: An MMP-9 mutant without gelatinolytic activity as a novel TIMP-1antagonist. FASEB J 14: 1671-1673, 2000.

26. Wach F, Eyrich AM, Wustrow T, Krieg T and Hein R: Comparison of migration and invasiveness of epithelial tumor and melanoma cells in vitro. J Dermatol Sci 12: 118-126, 1996.

27. Wach F, Hein R, Mann-Grill BC and Krieg T: Inhibition of fibroblast chemotaxis by superoxide dismutase. Eur J Cell Biol 44: 124-127, 1987.

28. Matrisian LM: Metalloproteinases and their inhibitors in matrix remodeling. Trends Genet 6: 121-125, 1990. 
29. Karelina TV, Hruza GJ, Goldberg GI and Eisen AZ: Localization of 92-kDa type IV collagenase in human skin tumors: comparison with normal human fetal and adult skin. J Invest Dermatol 100: 159-165, 1993.

30. Stetler-Stevenson WG, Liotta LA and Kleiner DE Jr: Extracellular matrix 6: role of matrix metalloproteinases in tumor invasion and metastasis. FASEB J 7: 1434-1441, 1993.

31. Nguyen M, Arkell J and Jackson CJ: Human endothelial gelatinases and angiogenesis. Int J Biochem Cell Biol 33: 960-970, 2001.

32. Rozanov DV, Savinov AY, Golubkov VS, Tomlinson S and Strongin AY: Interference with the complement system by tumor cell membrane type-1 matrix metalloproteinase plays a significant role in promoting metastasis in mice. Cancer Res 66: 6258-6263, 2006.

33. Houghton AM, Grisolano JL, Baumann ML, et al: Macrophage elastase (matrix metalloproteinase-12) suppresses growth of lung metastases. Cancer Res 66: 6149-6155, 2006.

34. Fingleton B: Matrix metalloproteinases: roles in cancer and metastasis. Front Biosci 11: 479-491, 2006.

35. Deryugina EI and Quigley JP: Matrix metalloproteinases and tumor metastasis. Cancer Metastasis Rev 25: 9-34, 2006.

36. Soreide K, Janssen EA, Korner H and Baak JP: Trypsin in colorectal cancer: molecular biological mechanisms of proliferation, invasion, and metastasis. J Pathol 209: 147-156, 2006.

37. Jodele S, Blavier L, Yoon JM and De Clerck YA: Modifying the soil to affect the seed: role of stromal-derived matrix metalloproteinases in cancer progression. Cancer Metastasis Rev 25: 35-43, 2006.

38. Wagenaar-Miller RA, Gorden L and Matrisian LM: Matrix metalloproteinases in colorectal cancer: is it worth talking about? Cancer Metastasis Rev 23: 119-135, 2004.

39. Overall $\mathrm{CM}$ and Kleifeld O: Towards third generation matrix metalloproteinase inhibitors for cancer therapy. Br J Cancer 94: 941-946, 2006

40. Fingleton B: Matrix metalloproteinase inhibitors for cancer therapy: the current situation and future prospects. Expert Opin Ther Targets 7: 385-397, 2003.

41. Fisher JF and Mobashery S: Recent advances in MMP inhibitor design. Cancer Metastasis Rev 25: 115-136, 2006.
42. Lubbe WJ, Zhou ZY, Fu W, et al: Tumor epithelial cell matrix metalloproteinase 9 is a target for antimetastatic therapy in colorectal cancer. Clin Cancer Res 12: 1876-1882, 2006.

43. Björklund M and Koivunnen E: Gelatinase-mediated migration and invasion of cancer cells. Biochim Biophys Acta 1755: 37-69, 2005.

44. Aimes RT and Quigley JP: Matrix metalloproteinase-2 is an interstitial collagenase. Inhibitor-free enzyme catalyzes the cleavage of collagen fibrils and soluble native type I collagen generating the specific 3/4- and 1/4-length fragments. J Biol Chem 270: 5872-5876, 1995 .

45. Xu X, Chen Z, Wang Y, Yamada Y and Steffensen B: Functional basis for the overlap in ligand interactions and substrate specificities of matrix metalloproteinases-9 and -2 . Biochem $\mathbf{J}$ 392: 127-134, 2005.

46. Patterson ML, Atkinson SJ, Knauper V and Murphy G: Specific collagenolysis by gelatinase A, MMP-2, is determined by the hemopexin domain and not the fibronectin-like domain. FEBS Lett 503: 158-162, 2001

47. Issa $\mathrm{R}$, Zhou $\mathrm{X}$, Trim N, et al: Mutation in collagen-1 that confers resistance to the action of collagenase results in failure of recovery from CCl4-induced liver fibrosis, persistence of activated hepatic stellate cells, and diminished hepatocyte regeneration. FASEB J 17: 47-49, 2003.

48. Morodomi T, Ogata Y, Sasaguri Y, Morimatsu M and Nagase $\mathrm{H}$ : Purification and characterization of matrix metalloproteinase-9 from U937 monocytic leukaemia and HT1080 fibrosarcoma cells. Biochem J 285: 603-611, 1992.

49. Lelongt B, Bengatta S, Delauche M, Lund LR, Werb Z and Ronco PM: Matrix metalloproteinase- 9 protects mice from anti-glomerular basement membrane nephritis through its fibrinolytic activity. J Exp Med 193: 793-802, 2001.

50. Murphy G, Cockett MI, Ward RV and Docherty AJ: Matrix metalloproteinase degradation of elastin, type IV collagen and proteoglycan. A quantitative comparison of the activities of $95 \mathrm{kDa}$ and $72 \mathrm{kDa}$ gelatinases, stromelysins- 1 and -2 and punctuated metalloproteinase (PUMP). Biochem J 277: 277-279, 1991.

51. Fridman R, Toth M, Chvyrkova I, Meroueh SO and Mobashery S: Cell surface association of matrix metalloproteinase-9 (gelatinase B). Cancer Metastasis Rev 22: 153-166, 2003. 